\title{
The significance of diagnosis and treatment planning in periapical lesion overfilled with calcium hydroxide paste
}

\author{
Kyoung-Hwa Jung ${ }^{1,2}$, Eun-Young Kwon', Youn-Kyung Choi', So-Yeun Kim¹, Hye-Mi Jeon', Jeong-Kil Park ${ }^{2 *}$ \\ 'Dental Clinic Center, Pusan National University Hospital, Busan, Republic of Korea \\ ${ }^{2}$ Department of Conservative Dentistry, School of Dentistry, Pusan National University, Yangsan, Republic of Korea
}

Calcium hydroxide has been widely used for root canal dressing material in endodontic treatment. This report describes that when the accurate diagnosis and proper nonsurgical endodontic retreatment is applied to periapical lesion with accidentally extruded calcium hydroxide paste, the lesion can be successfully treated. Overfilled calcium hydroxide can affect the healing process, so the overextension of calcium hydroxide agent should be avoided. (J Dent Rehabil Appl Sci 2021;37(2):95-100)

Key words: calcium hydroxide; periapical lesion

\begin{abstract}
서론
감염된 근관계에 존재하는 세균은 치수 및 치근 주위 질환의 발생과 밀접한 연관성을 가지고 있으므로 근관치 료의 성공을 위해서는 근관 내 세균의 제거가 중요한 요 소가 되며, ${ }^{1}$ 이를 위해서 근관치료 과정 동안 기계-화학적 근관성형 및 근관 내 첩약을 시행한다.

특히, 치근단 병소를 가지고 있는 치아의 치료에는 수 산화칼슘 기반 근관 내 첩약제의 사용이 중요한데, ${ }^{2}$ 임 상가들이 주로 많이 사용하고 있는 근관 내 첩약제로 Calcipex II (Techno-Dent, Bangkok, Thailand)가 있다. Calcipex II는 수산화칼슘 $\left(\mathrm{Ca}(\mathrm{OH})_{2}\right)$, 황산바륨 $\left(\mathrm{BaSO}_{4}\right)$ 과 프로필렌 글라이콜(propylene glycol $\left.\left(\mathrm{C}_{3} \mathrm{H}_{8} \mathrm{O}_{2}\right)\right)$ 을 함 유하는 수산화칼슘 기반 수용성 근관 내 첩약제로서, 근 관내에 쉽게 적용 및 제거가 가능하며, $\mathrm{pH}$ 가 12.4 에 달 하는 높은 알칼리성 특성으로 인해 항미생물 효과와 골 재생 효과를 제공한다. ${ }^{3}$ 하지만, 근관 내 첩약 과정 중 Calcipex II가 과충전되는 경우가 종종 보고되고 있
\end{abstract}

${ }^{*}$ Correspondence to: Jeong-Kil Park

Professor, Department of Conservative Dentistry, Pusan National University, 20, Geumo-ro, Mulgeum-eup, Yangsan, 50612, Republic of Korea

Tel: +82-55-360-5221, Fax: +82-55-360-5214, E-mail: jeongkil@pusan.ac.kr

Received: January 7, 2021/Last Revision: February 9, 2021/Accepted: March 12, 2021
는데, Calcipex II가 치근단 조직으로 퍼져나갔을 경우 Calcipex II에 존재하는 미립제 고분자 수지(fine granular polymer resin) 물질에 대한 이물 반응(foreign body reaction)이 일어나 결국 만성 육아종성 병소가 발생하는 증례들이 보고되고 있다. ${ }^{4-6}$

치외치는 치아의 교합면에 돌출된 부가적인 교두나 돌 기를 가진 결절 형태의 발육 이상으로, ${ }^{7} 1$ - $4 \%$ 정도의 유 병율을 보이며 아시아 계통 인종에서 많이 발생하고, 대 구치, 견치, 전치에서도 발생하지만 소구치에서 더 높은 유병율을 보이며 양측으로 발생하는 경우가 많다. ${ }^{8}$ 교합 면으로 돌출된 교두는 교합력에 의해 마모되거나 파절될 수 있고 이로 인해 치수괴사나 치근단 염증을 발생시킬 수 있으므로 임상적으로 중요하다. ${ }^{9}$ 특히, 치근단이 아직 발육을 하지 못해 열린 시기에 돌기의 파절이 많이 발생 하게 되므로 이를 치료하는 것도 쉽지 않다. ${ }^{10}$

저자는 치외치로 인한 치근단 병소를 가진 하악 소구 치의 치료 도중 근관 내에 첩약한 Calcipex II가 치근단 조직으로 과충전된 환자의 수술적 치료를 의뢰 받았고,

Copyright (C) 2021 The Korean Academy of Stomatognathic Function and Occlusion. (c) It is identical to Creative Commons Non-Commercial License. 
이를 보존적으로 치료하였으므로 본 증례를 소개하고자 한다.

\section{증례 보고}

18세 여자 환자가 수 차례의 근관치료를 시행 받았음 에도 불구하고 해당 치아 주변에 불편감이 지속되며 부 종까지 발생하였다는 것을 주소로 내원하였다. 이전에 치료 받았던 치과에서 치근단 부위에 치료 재료가 넘어 가 수술이 필요할 수 있으므로 대학 병원에서 치료 받는 것이 좋겠다는 설명을 듣고 내원했다고 하였으며, 의뢰서 상에서도 치외치에 발생한 치근단 병소를 치료하는 중에 치근단 주위로 넘어간 Calcipex II로 인해 통증 조절이 되 지 않으므로 이에 대한 수술적 치료를 위해 본원으로 의 뢰한다고 기록되어 있었다. 임상 검사 및 방사선 검사 상 하악좌측제 2 소구치에 근관치료를 시행하는 도중이었고, 커다란 치근단 병소가 형성되어 있었으며 큰 치근단 병 소 내에 소량의 방사선불투과상 물질이 퍼져 있는 것을 확인할 수 있었다(Fig. $1 \mathrm{~A}, 2 \mathrm{~A}, 3 \mathrm{~A}$ ). 구강 내 검사 상, 반 대편 치아인 하악우측제 2 소구치에 치외치가 존재하였으 며(Fig. 1B), 하악좌측제 2 소구치의 협측 치은의 부종이 확인되었으며 촉진 시에 통증을 호소하였다. 치아를 타 진해보았을 때 타진에 대한 통증을 호소하였으며 평상 시 자극이 없을 때도 해당 치아 근처에 욱씬거리는 증상 이 존재한다고 하였다.
하악좌측제 2 소구치의 급성 치근단 농양으로 진단 내 리고 재근관치료를 시행하기로 결정하였다. 내원 당일 러 버댐 격리하에 근관와동을 채우고 있는 임시 충전재를 제거한 후 근관 내 상태를 관찰해보았을 때, 근관와동을 통해 다량의 농이 배출되는 것을 확인할 수 있었다(Fig. 1C). 그 후 근관세척을 시도하였는데, 근관세척을 위해 적용한 주사침이 근단부 주변까지 충분히 도달하지 못하 고 치근 중간 $1 / 3$ 지점 상방 정도까지만 도달되는 것을 확인할 수 있었다. 근관와동 형성이 충분치 못해 그 동안 시행해온 수 차례의 근관세척에도 지속적인 부종 및 통 증이 발생했을 수도 있다는 판단이 들었기에 우선 충분 한 근관세척을 통해서 통증을 조절해보고자 먼저 주사침 이 근단부 주변까지 직선 접근이 가능할 수 있도록 근관 와동 부위를 충분히 더 삭제한 후에 회전식 $\mathrm{NiTi}$ 파일을 이용하여 근관성형 및 근단부 주변까지 차아염소산나트 륨 $(\mathrm{NaOCl})$ 을 이용한 근관세척을 시행하였다. 그 후 근 관 내 첩약제로써 Calcipex II를 근관 내에 적용하고 임시 가봉하였다(Fig. 2B).

3 일 후 재 내원 시 환자는 통증이 많이 줄어 평상시 가 만히 있을 때 아픈 느낌은 전혀 없다고 하였다. 임상검사 상 협측 치은의 부종은 사라졌으며, 촉진 시 통증도 호소 하지 않았고, 타진 시에 약간의 통증만 호소하였다. 처음 환자를 의뢰한 임상가는 기존에 존재했던 커다란 치근 단 병소와 치근단 조직으로 흘러 들어간 근관 첩약제로 인해 급성 치근단 농양이 발생하였다고 판단하여, 치근
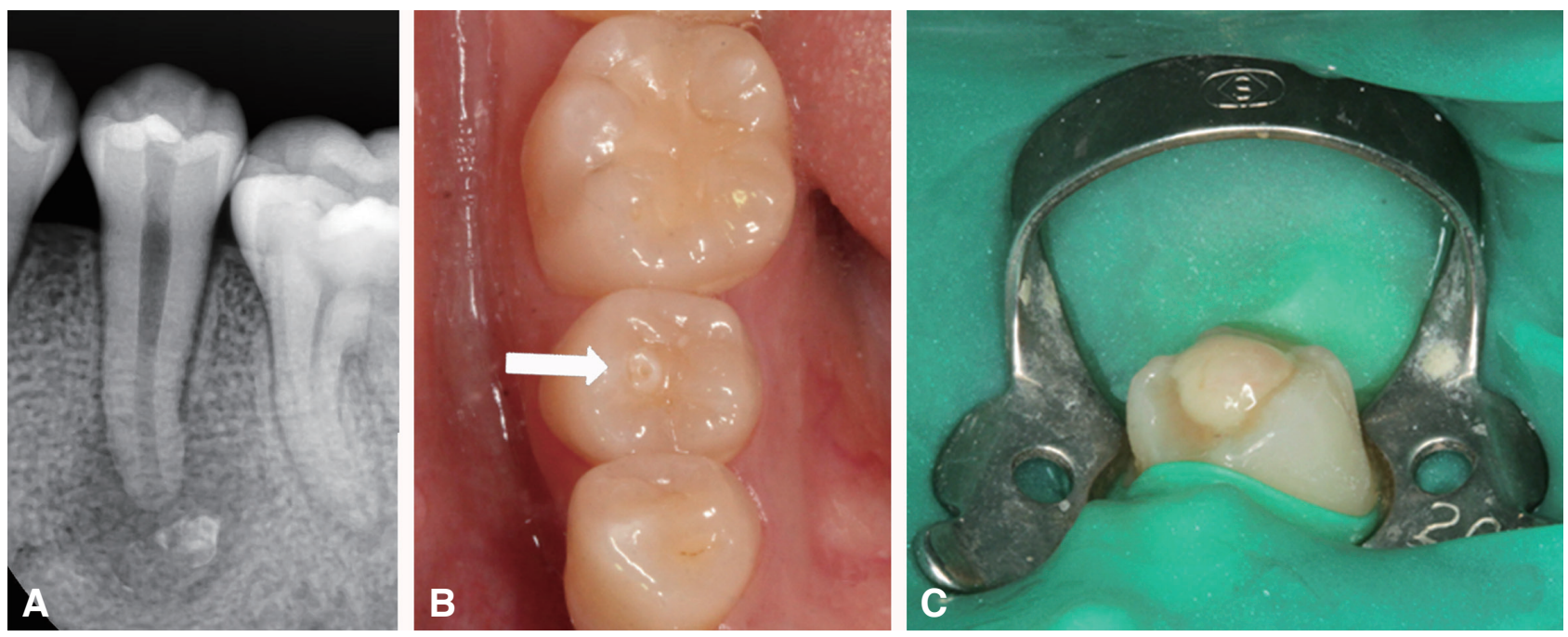

Fig. 1. (A) Preoperative radiograph of mandibular left second premolar, (B) Photograph of dens evaginatus (arrow) on mandibular right second premolar, (C) Photograph showing a discharge of pus through pulp chamber of mandibular left second premolar. 

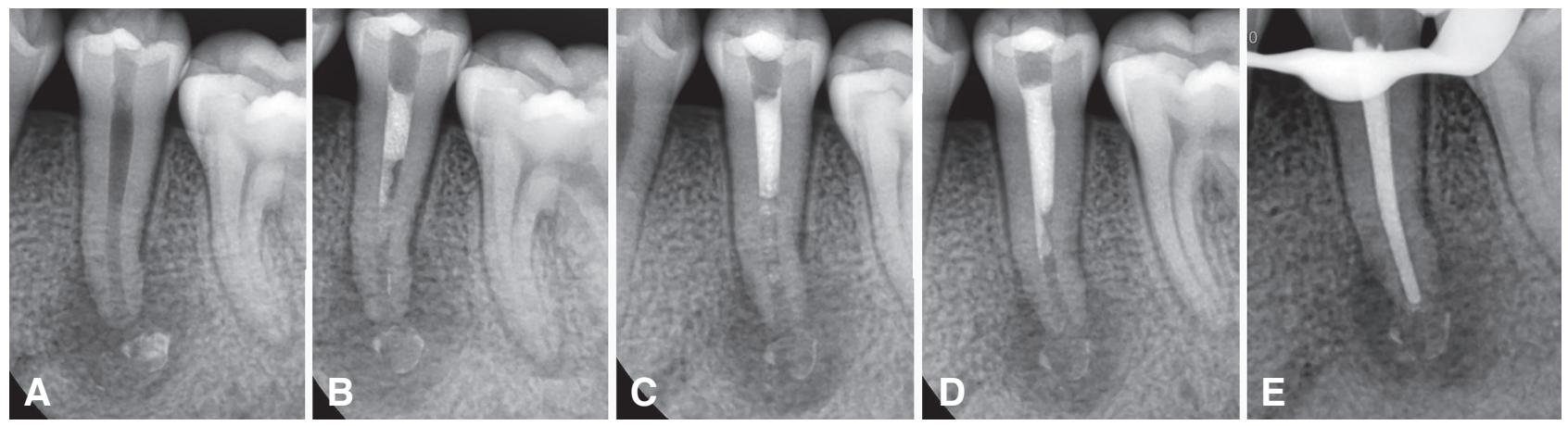

Fig. 2. Radiographs during endodontic treatment. (A) Preoperative radiograph, (B) Radiograph of the first visit. (C) Radiograph of the second visit, (D) Radiograph of the third visit, (E) Radiograph of the fourth visit. The canal filling was done.
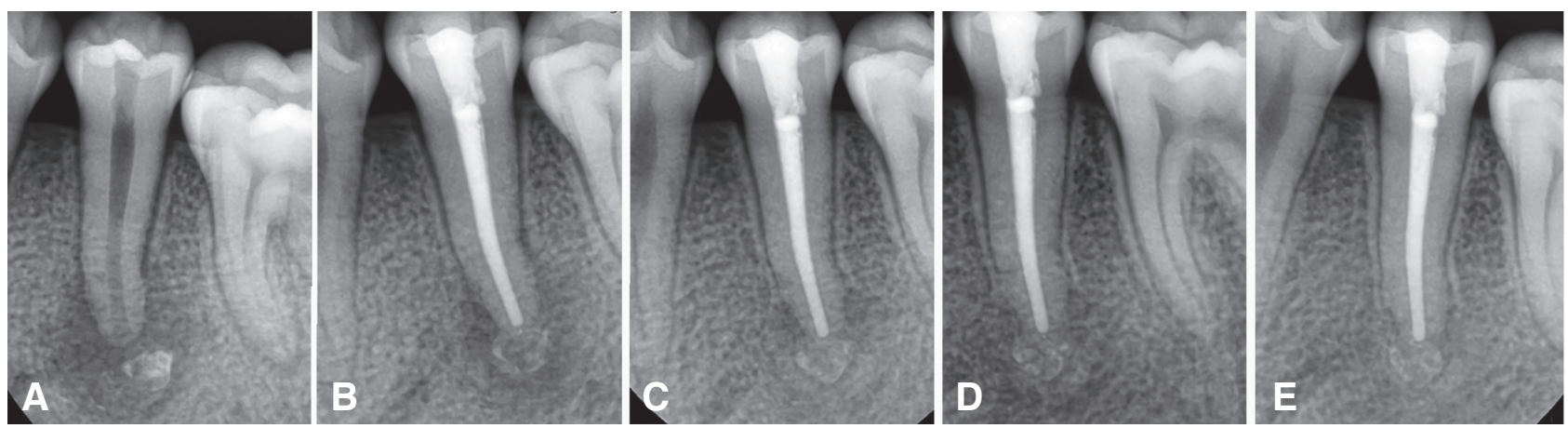

Fig. 3. Radiographs. (A) Preoperative radiograph, (B) 6 months follow up radiograph, (C) 12 months follow up radiograph, (D) 18 months follow up radiograph, (E) 24 months follow up radiograph.

단 부위에 존재하는 근관 첩약제에 대한 수술적 처치를 시행해줄 것을 의뢰하였지만, 처음 내원 시 충분히 확장 시킨 근관와동을 통한 일반적인 근관세척만으로도 증상 조절이 일부 일어나는 것을 보고 근단부로 넘어간 Calcipex II에 대한 처치는 시행하지 않고 일반적인 근관치료 를 더 시행해보기로 하였다. 환자가 호소하는 증상이 사 라질 때까지 1 주일 간격으로 근관세척 및 근관 내 첩약을 시행하였다(Fig. 2C, 2D).

다음 내원 시 환자는 타진에 대해서 통증을 호소하지 않았으며 불편감이 전혀 없다고 하여 근관 충전을 시행 하였으며, 근관와동 부위는 복합레진으로 충전하였다

(Fig. 2E).

치근단 병소의 크기가 크며, 치근단 조직에 남아있는 Calcipex II가 의도하지 않은 반응을 일으킬 가능성이 있 어 그 후 6 개월, 12 개월, 18 개월, 24 개월 후 추적 검사를 시행하였다(Fig. 3B, 3C, 3D, 3E). 환자는 불편감을 호소 하지 않았으며 방사선사진 상 치근단 조직에 Calcipex II 는 남아있는 채로 골 재생이 지속적으로 일어나는 것을
확인할 수 있었다.

\section{고찰}

이번 증례에서 환자는 이미 하악좌측제 2 소구치의 교 합면에 근관와동을 형성한 채로 내원하였지만 반대측인 하악우측제 2 소구치의 교합면을 관찰하였을 때 추가적 인 교두를 확인할 수 있었고(Fig. 1B), 깊은 치아 우식이 존재하지 않은 채로 커다란 치근단 병소가 생겼다는 점 에서 치외치의 추가 교두의 마모 또는 파절로 인해 치수 괴사 및 치근단 병소가 발생한 것으로 판단할 수 있었다. 방사선사진상 치근단공이 상당히 넓고 치근단 병소의 크 기도 큰 편이라 Calcipex II의 치근단 부위로의 주입이 더 쉽게 일어났을 것으로 생각된다.

Calcipex II의 과충전이 발생했던 여러 증례를 살펴보 면 이와 관련된 증상, 치료 방법 및 치료 결과들이 다양하 다. Kim 등은 상악 소구치와 대구치를 치료하던 중 치근 단 조직으로 넘어간 다량의 Calcipex II가 18개월 후 임상 
검사 상 상악동 내로 점차 이동하여 상악동염이 발생한 증례를 보고하였고, 결국 수술적인 방법을 통해 이와 관 련해 발생한 구치부 통증을 해소시킬 수 있었다. ${ }^{4}$ 반면에, Calcipex II가 근단 주위 조직으로 넘어가더라도 어떠한 증상도 일으키지 않았던 증례 보고도 있는데, 하악소구 치를 치료하던 도중 근관세척 후 근관 내 첩약제로 적용 한 수산화칼슘 분말과 황산바륨 분말 혼합물이 치근단 조직으로 넘어갔으나 특별한 증상이 발생하지 않아 근관 충전을 시행하였고, 3 년 동안의 추적관찰 동안에도 통증 이 발생하지 않았고 치근단 병소 또한 치유가 되었던 증 례보고도 있다. ${ }^{11}$

본 증례에서, 환자는 지속적인 근관치료에도 불구하고 급성 치근단 농양과 관련한 증상이 해결되지 않았으며, 심지어 근관치료 도중 치근단 조직으로 넘어간 Calcipex II로 인해 수술적인 방법을 이용해야 증상 조절이 될 수 있다고 믿고 내원한 상태라 심리적으로 몹시 불안한 상 태였다. 하지만, 근관와동을 충분히 넓게 확장시킨 술식 을 통해 치근첨 부위 근처까지 근관세척액의 주사침의 직선 도달이 가능해졌고, 이로 인해 충분한 근관세척이 이루어짐으로 인해 성공적인 비외과적 근관치료가 행해 질 수 있었으며, 더욱이 치근단 조직으로 넘어간 과충전 된 Calcipex II의 양이 상대적으로 소량이었던 점에서 결 과적으로 수술적인 치료 없이 증상을 해결할 수 있었던 것으로 생각된다. 장기간의 추적 검사 결과에도 환자가 느끼는 통증 등의 증상은 여전히 없었고 방사선사진 상 의 치근단 병소가 치유되는 것을 확인할 수 있었다.

일반적으로, 근관치료의 성공률은 $86-98 \%$ 정도로 보 고되고 있다. ${ }^{12}$ 근관치료를 실패하게 하는 요인들은 무 수히 많은데 그 중에서도 세균의 잔존, 적절하지 못한 근 관충전, 과충전, 치관부 부위에서의 누출, 치료하지 못한 근관, 치료 과정에서의 오류, 잘못된 기구 조작으로 인 한 합병증 등이 근관치료의 일반적인 실패 원인으로 알 려져 있다. ${ }^{13}$ 이러한 요인들에 대한 연구에서, $\operatorname{Lin}$ 등 $^{14}$ 과 Siqueira ${ }^{15}$ 는 근관계나 치근단 조직에 잔존하는 세균 감 염으로 인해 근관치료가 주로 실패한다고 하였으며, 기 구 파절이나 천공, 과충전, 저충전, ledge 형성과 같은 술 식 상의 오류는 잔존하는 감염원이 존재하지 않는 한 근 관치료의 결과에 큰 영향을 주지는 않는다고 보고하였 다. 또한, 비외과적인 재근관치료와 외과적인 근관치료의 치료 결과를 비교 연구한 Torabinejad 등 ${ }^{16}$ 은 외과적인 근 관치료가 초기 치유에 있어서는 좀 더 나은 성공률을 보 여주었을지라도 검진 시기가 늘어날수록 비외과적인 재
근관치료의 성공률이 더 높았다는 연구 결과를 보고하였 다.

이러한 연구 결과들에 기반하였을 때, 이번 증례보고는 치근단 조직에 과충전된 Calcipex II에 대해 외과적 근관 치료를 의뢰 받았음에도 불구하고 올바른 진단과 적절한 근관와동 형성 및 근관확대를 시행함으로써 치근단 조 직에 과충전된 Calcipex II에 대한 외과적인 처치 없이 비 외과적인 근관치료만으로 치근단에 발생한 급성 농양을 성공적으로 치료하였다는 점에서 의의를 가진다고 할 수 있다.

하지만, 이번 증례보고에서도 치근단 부위의 방사선불 투과성 물질이 시간이 경과함에도 불구하고 사라지지 않 고 여전히 남아있는 것을 확인할 수 있었다. 이것은 Calcipex II에 포함된 불용성 물질인 황산바륨 때문인데, 이 물질이 오랫동안 남아있음으로 인해 골치유에 대한 방사 선학적인 해석에 방해가 될 수 있고, ${ }^{17}$ 더 나아가 치근첨 을 넘어간 수산화칼슘의 존재가 치근단 병소의 조기 치 유를 어렵게 하는 원인이 될 수 있다는 보고도 있다. ${ }^{18}$

따라서, 임상가는 치근단공이 넓은 치아의 근관치료를 하는 도중에는 더 각별히 치근첨을 넘어 근관 내 첩약제 가 주입되는 일이 발생하지 않도록 주의해야 할 것이며, 의도치 않게 근단부 넘어로 약제가 주입되었다 하더라도 처음부터 수술적인 제거 방법을 무리하게 시도하지 않고 보존적인 근관치료 방법으로도 증상을 해결할 수 있는지 에 대해서 올바른 진단을 내리고 현명한 판단을 할 수 있 어야 한다. 또한, 보존적인 비외과적 재근관치료를 접근 방법으로 선택하였을 경우, 병소의 치유에 대한 치료 결 과의 안정성을 확인하기 위해 장기간에 걸친 추적 관찰 을 시행해보는 것이 필요할 것이다.

\section{결론}

본 증례는 근관치료 도중 사용한 수산화칼슘제재가 치근첨을 넘어 치근단 병소로 넘어간 경우, 올바른 진단 을 통해 수술적인 치료가 아닌 적절하게 적용된 비외과 적인 근관치료만으로도 만족할만한 치료 결과를 얻을 수 있다는 것을 보여주는데 그 의의가 있다. 임상가는 이러 한 증례를 치료함에 있어 적절한 치료 방법을 현명하게 선택할 수 있어야 하며, 나아가 근관치료 도중 치근첨을 넘어 근관 내 첩약제가 주입되는 일이 발생하지 않도록 사전에 각별한 주의를 기울여야 할 것이다. 


\section{Acknowledgements}

This work was supported by clinical research grant from Pusan National University Hospital in 2020.

\section{ORCID}

Kyoung-Hwa Jung https://orcid.org/0000-0002-8305-0016

Eun-Young Kwon https://orcid.org/0000-0001-9555-0360

Youn-Kyung Choi https://orcid.org/0000-0003-1491-2986

So-Yeun Kim https://orcid.org/0000-0002-3043-2723

Hye-Mi Jeon https://orcid.org/0000-0003-0007-5662

Jeong-Kil Park https://orcid.org/0000-0001-6333-8138

\section{References}

1. Kakehashi S, Stanley HR, Fitzgerald RJ. The effects of surgical exposures of dental pulps in germ-free and conventional laboratory rats. Oral Surg Oral Med Oral Pathol 1965;20:340-9.

2. Kim JW, Cho KM, Park SH, Song SG, Park MS, Jung HR, Song JY, Kim YS, Lee SK. Overfilling of calcium hydroxide based paste Calcipex II produced a foreign body granuloma without acute inflammatory reaction. Oral Surg Oral Med Oral Pathol Oral Radiol Endod 2009;107:e73-6.

3. Hosoya N, Kurayama H, Iino F, Arai T. Effects of calcium hydroxide on physical and sealing properties of canal sealers. Int Endod J 2004;37:178-84.

4. Kim JW, Cho KM, Park SH, Park SR, Lee SS, Lee SK. Chronic maxillary sinusitis caused by root canal overfilling of Calcipex II. Restor Dent Endod 2014;39:63-7.

5. Kim SM, Yoo YJ, Lee SK. Birefringence detection of Calcipex II endodontic material in chronic granulomatous lesion of periapical cyst. Korean J Oral Maxillofac Pathol 2016;40:775-9.

6. Shin Y, Roh BD, Kim Y, Kim T, Kim H. Accidental injury of the inferior alveolar nerve due to the extrusion of calcium hydroxide in endodontic treatment: a case report. Restor Dent Endod 2016;41:637.

7. Levitan ME, Himel VT. Dens evaginatus: literature review, pathophysiology, and comprehensive treatment regimen. J Endod 2006;32:1-9.
8. Hill FJ, Bellis WJ. Dens evaginatus and its management. Br Dent J 1984;156:400-2.

9. Chen JW, Huang GT, Bakland LK. Dens evaginatus: current treatment options. J Am Dent Assoc 2020;151:358-67.

10. Stecker S, DiAngelis AJ. Dens evaginatus: a diagnostic and treatment challenge. J Am Dent Assoc 2002;133:190-3

11. Orucoglu H, Cobankara FK. Effect of unintentionally extruded calcium hydroxide paste including barium sulfate as a radiopaquing agent in treatment of teeth with periapical lesions: report of a case. J Endod 2008;34:888-91.

12. Song M, Kim HC, Lee W, Kim E. Analysis of the cause of failure in nonsurgical endodontic treatment by microscopic inspection during endodontic microsurgery. J Endod 2011;37:1516-9.

13. Tabassum S, Khan FR. Failure of endodontic treatment: The usual suspects. Eur J Dent 2016;10:1447.

14. Lin LM, Skribner JE, Gaengler P. Factors associated with endodontic treatment failures. J Endod 1992;18:625-7.

15. Siqueira JF Jr. Aetiology of root canal treatment failure: why well-treated teeth can fail. Int Endod J 2001;34:1-10.

16. Torabinejad M, Corr R, Handysides R, Shabahang $\mathrm{S}$. Outcomes of nonsurgical retreatment and endodontic surgery: a systematic review. J Endod 2009; 35:930-7.

17. Alaçam T, Görgül G, Omürlü H. Evaluation of diagnostic radiopaque contrast materials used with calcium hydroxide. J Endod 1990;16:365-8.

18. Vernieks AA, Messer LB. Calcium hydroxide induced healing of periapical lesions: a study of 78 non-vital teeth. J Br Endod Soc 1978;11:61-9. 


\section{수산화칼슘제재의 과충전이 발생한 치근단 병소 증례에서 진단과 치료 계획의 중요성}

정경화 ${ }^{1,2}$ 임상부교수, 권은영 ${ }^{1}$ 임상부교수, 최윤경 ${ }^{1}$ 임상부교수, 김소연 ${ }^{1}$ 임상부교수, 전혜미 ${ }^{1}$ 임상부교수, 박정길 ${ }^{2 *}$ 교수 ${ }^{1}$ 부산대학교병원 치과진료센터

${ }^{2}$ 부산대학교 치의학전문대학원 치과보존학교실

수산화칼슘제재는 근관치료 과정 동안 근관 내 첩약제로서 널리 사용되고 있다. 이번 증례 보고에서는 근관 세척제로 사 용된 수산화칼슘제재가 치근단 병소로 의도치 않게 과충전된 치아에 대해 정확한 진단과 적절하게 행해진 비외과적인 재근관치료를 통해 성공적으로 치료한 증례를 보고하고자 한다. 과충전된 수산화칼슘제재가 치근단 병소의 치유 과정 에 영향을 줄 수 있으므로 수산화칼슘제재의 과충전이 발생하지 않도록 주의를 기울여야 한다.

(구강회복응용과학지 2021;37(2):95-100)

주요어: 수산화칼슘; 치근단 병소

*교신저자: 박정길

(50612)경상남도 양산시 물금읍 금오로 20 부산대학교 치과보존학교실

Tel: 055-360-5221 | Fax: 055-360-5214 | E-mail: jeongkil@pusan.ac.kr

접수일: 2021년 1월 7일 | 수정일: 2021년 2월 9일 || 채택일: 2021년 3월 12일

100 